\title{
IRES-mediated translation of foot-and- mouth disease virus (FMDV) in cultured cells derived from FMDV-susceptible and -insusceptible animals
}

\author{
Takehiro Kanda ${ }^{1}$, Makoto Ozawa ${ }^{1,2}$ and Kyoko Tsukiyama-Kohara ${ }^{1,2^{*}}$
}

\begin{abstract}
Background: Foot-and-mouth disease virus (FMDV) possess a positive sense, single stranded RNA genome. Internal ribosomal entry site (IRES) element exists within its $5^{\prime}$ untranslated region ( $\left.5^{\prime} U T R\right)$ of the viral RNA. Translation of the viral RNA is initiated by internal entry of the $40 \mathrm{~S}$ ribosome within the IRES element. This process is facilitated by cellular factors known as IRES trans-acting factors (ITAFs).

Foot-and-mouth disease (FMD) is host-restricted disease for cloven-hoofed animals such as cattle and pigs, but the factors determining the host range have not been identified yet. Although, ITAFs are known to promote IRES-mediated translation, these findings were confirmed only in cells derived from FMDV-insusceptible animals so far.

We evaluated and compared the IRES-mediated translation activities among cell lines derived from four different animal species using bicistronic luciferase reporter plasmid, which possesses an FMDV-IRES element between Renilla and Firefly luciferase genes. Furthermore, we analyzed the effect of the cellular factors on IRES-mediated translation by silencing the cellular factors using siRNA in both FMDV-susceptible and -insusceptible animal cells.

Results: Our data indicated that IRES-mediated translational activity was not linked to FMDV host range. ITAF 45 promoted IRES-mediated translation in all cell lines, and the effects of poly-pyrimidine tract binding protein (PTB) and eukaryotic initiation factor 4E-binding protein 1 (4E-BP1) were observed only in FMDV-susceptible cells. Thus, PTB and 4E-BP1 may influence the host range of FMDV.
\end{abstract}

Conclusions: IRES-mediated translation activity of FMDV was not predictive of its host range. ITAF 45 promoted IRES-mediated translation in all cells, and the effects of PTB and 4E-BP1 were observed only in FMDV-susceptible cells.

Keywords: FMDV, IRES, ITAF, ITAF 45, 4E-BP1, PTB, Translation

\section{Background}

Foot-and-mouth disease (FMD) is a highly contagious infectious disease in cloven-hoofed animals such as cattle, pigs, and other related species [1]. It is considered an endemic in several countries in Asia, Africa, and South America. Typical clinical signs of FMD include vesicle formation, and erosion of cutaneous mucosae and hairless parts of the skin proximal to the mouth and

\footnotetext{
* Correspondence: kkohara@vet.kagoshima-u.ac.jp

'Department of Animal Hygiene, Joint Facility of Veterinary Medicine, Kagoshima University, Kagoshima, Kagoshima, Japan

${ }^{2}$ Transboundary Animal Disease Center, Joint Facility of Veterinary Medicine, Kagoshima University, Kagoshima, Kagoshima, Japan
}

the hoofs. While FMD is rarely lethal in adult animals, it can induce myocarditis in newborn animals, which leads to high mortality [2]. In countries with endemic FMD, FMD-related mortality of young animals and decreased productivity (reduced milk production and animal weight loss) in adult animals can lead to major economic losses. In industrialized countries that are normally free of FMD, the costs associated with the control and eradication of an outbreak can reach several billion US dollars, which also include indirect losses due to trade restrictions on animal products [3]. 
FMDV possesses a positive sense, single stranded RNA as its viral genome and belongs to the Aphtovirus genus of the Picornaviridae family. FMDV possesses an internal ribosomal entry site (IRES) element within the $5^{\prime}$ untranslated region (5'UTR), and virus proteins are synthesized by IRES-mediated translation $[1,4]$. It is known that, like FMDV, poliovirus (PV) and encephalomyocarditis virus (EMCV) belonging to the Picornaviridae family, and hepatitis $\mathrm{C}$ virus (HCV) belonging to the Flaviviridae family, possesses a virus-specific IRES element within the 5'UTR, and virus proteins are synthesized by IRESmediated translation $[5,6]$. According to the RNA secondary structure, picornavirus IRESs can be classified into five types designated I (PV), II (FMDV), III (hepatitis A virus), IV (HCV-like), and V (aichivirus-like) [7]. Although FMD primarily affects cloven-hoofed animals such as cattle and pigs [1], the factors that determine the host range of FMDV have not yet been identified. Usually, eukaryotic mRNA is translated by cap-dependent translation, which is initiated by recognition of the cap structure at the $5^{\prime}$ end of the mRNA by the $43 \mathrm{~S}$ ribosome [8]. Virus mRNA with a short 5'UTR ( $<100$ nucleotides) containing no AUG can facilitate protein synthesis in a cap-dependent manner, similar to most types of eukaryotic mRNAs $[5,6]$. Cap-independent translation is mediated by the IRES $[5,6]$ and involves 3 '-UTR cap-independent translation enhancer (3'-CITE)-mediated initiation $[9,10]$. $\mathrm{Vpg}$ interacts with the cap-binding protein eIF4E to modulate translation $[11,12]$. The translation of eukaryotic mRNA is halted or significantly suppressed by cleavage of eIF4G with picornavirus protease (e.g., PV $2 \mathrm{~A}^{\text {pro }}$ and FMDV $\mathrm{L}^{\text {pro }}$ ), whereas protein synthesis directed by PV or EMCV-IRES is stimulated [13, 14]. FMDV $L^{\text {pro }}$ can enhance translation driven by all picornavirus IRESs, even after inactivation of eIF2 by phosphorylation [15].

The FMDV-IRES element contains five domains, and each of these domains forms a specific three-dimensional conformation to directly bind to the $40 \mathrm{~S}$ ribosome and initiate IRES-mediated translation [16, 17]. In addition to canonical eukaryotic initiation factors (eIFs), which are essential to initiate cap-dependent translation, IRES transacting factors (ITAFs), which specifically bind to the individual domains of the IRES element and stabilize its three-dimensional structure, are required to facilitate IRES-mediated translation [18, 19]. In previous reports, it was revealed that $\mathrm{ITAF}_{45}$ and polypyrimidin tract binding protein (PTB) plays an important role in facilitating IRES-mediated translation of FMDV [20-22].

On the other hand, eukaryotic initiation factor 4E (eIF4E), a cap-binding protein, is an essential cellular factor that initiates cap-dependent translation; however, some viral mRNAs with IRESs can escape the eIF4E regulatory pathway [23]. The translation inhibitor, eIF4E-binding protein 1 (4E-BP1), binds eIF4E in its dephosphorylated form and is phosphorylated by stimulation with insulin or epidermal growth factors to dissociate from eIF4E [24, 25] after phosphorylation by mammalian target of rapamycin complex 1 (mTORC1) [26]. The free-eIF4E can promote cap-dependent translation by forming eIF4F with other eIFs [27]. However, once $4 \mathrm{E}-\mathrm{BP} 1$ is dephosphorylated due to stress, it binds to eIF4E tightly, and cap-dependent translation is suppressed because eIF4F cannot be formed [28, 29]. EMCV and PV have been reported to dephosphorylate 4E-BP1, which may block host protein synthesis [29]. Because eIF4E is not essential for some types of virus IRESmediated translation, it is possible that dephosphorylation of 4E-BP1 could facilitate IRES-mediated translation of FMDV [29-31].

However, these results were obtained in an experiment using cell lines derived from mice or hamsters, which are not the host animals of FMDV. Hence, whether these findings are also observed in cells derived from the FMDV host animals have not yet been analyzed.

Clove-hoofed animals are the main FMDV hosts, but the virus or cellular factors that determine the host range have not yet been identified. In this study, to analyze whether the host range of FMDV is determined by its IRES-mediated translation or not, we evaluated and compared IRES-mediated translation activities among the cell lines derived from different animal species, including both host and non-host animals (host animals: bovine and swine, non-host animals: human and canine). Furthermore, to confirm whether previous findings about ITAFs and 4E-BP1 were also observed in the host animal cells of FMDV, we analyzed the effect of the ITAFs and 4E-BP1 for IRES-mediated translation of FMDV in both host and non-host animal cells.

\section{Results}

Evaluation and comparison of IRES-mediated translation activity of FMVD in various animal cell lines

To evaluate IRES-mediated translational activity, we constructed a bicistronic reporter plasmid [30]. EcoRV and $\mathrm{HpaI}$ were used to excise the reporter gene from pRF/FMDV-IRES, which has an FMDV-IRES element between Renilla luciferase and firefly luciferase genes. The extracted reporter gene was then inserted into the pCAGGS/MCS(F) vector, as the CAG promoter is functional in most cell types [32]. This plasmid construct was named pCAGGS/FMDV-IRES (Fig. 1).

This plasmid was then transfected into cell lines derived from the kidney epithelium of different animal species (HEK293 cells: human, MDCK cells: canine, MDBK cells: bovine, and CPK cells: swine). Amongst the assessed animal species, bovine and swine cell lines were derived from animals that are the natural hosts for FMDV. The bicistronic mRNA that contains the FMDV-IRES element 


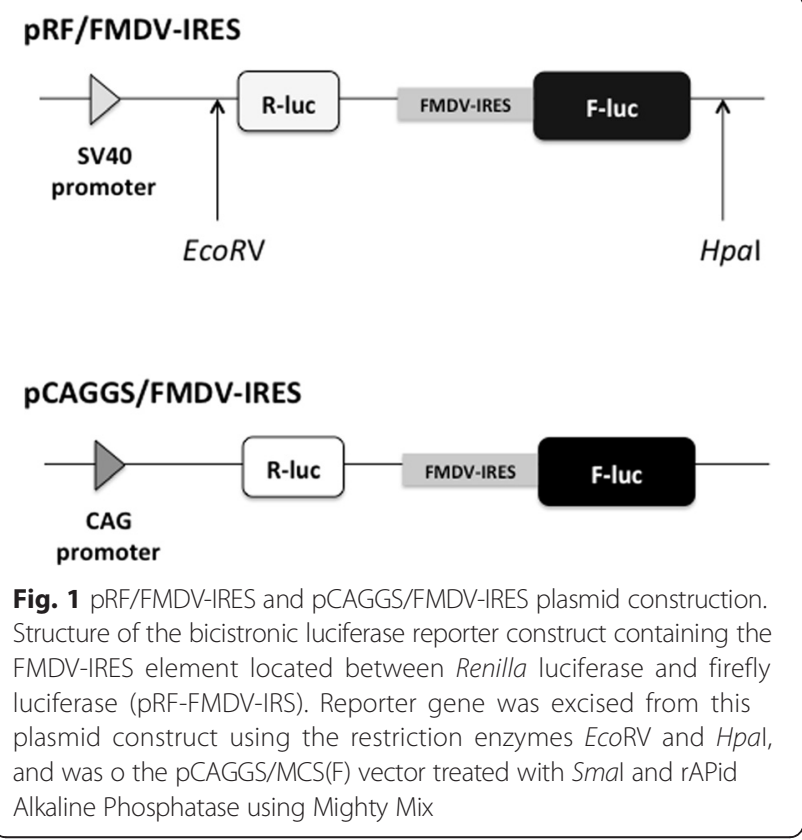

between Renilla luciferase and firefly luciferase genes was produced in the transfected cells. $24 \mathrm{~h}$ following transfection, both Renilla luciferase and firefly luciferase activities in the cells were serially measured. Renilla luciferase activity represented cap-dependent translation, and firefly luciferase activity represented IRES-mediated translation. To evaluate IRES-mediated translational activity, the ratio of IRES-mediated translation to cap-dependent translation was calculated (Fig. 2). It was assumed that IRESmediated translational activity of FMDV would be much higher in the cell lines derived from host animals of

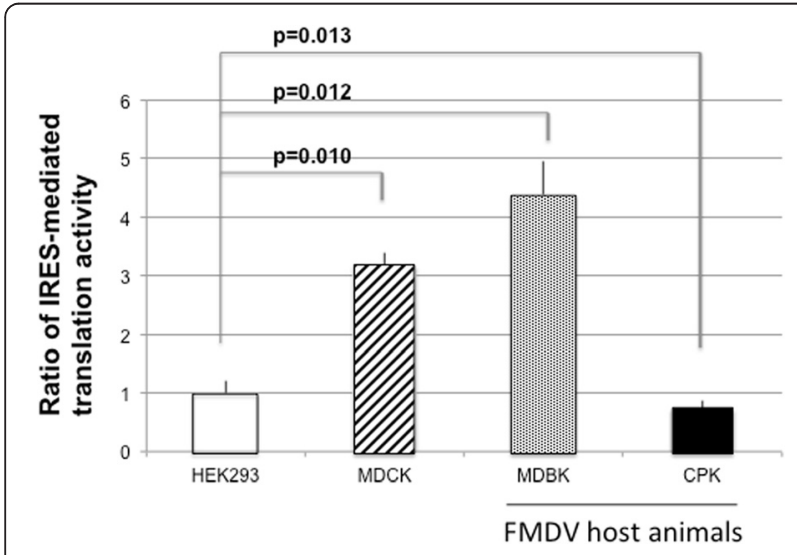

Fig. 2 Evaluation of IRES-mediated translation activity. HEK293, MDCK, MDBK, and CPK cells were transfected with pCAGGS/FMDV-IRES. $24 \mathrm{~h}$ following transfection, Renilla luciferase and firefly luciferase units were measured using the Dual-Luciferase Reporter Assay System, and the ratio of IRES-mediated translation activity to that in HEK293 cells was evaluated. Experiments were performed in triplicates and error bars indicate S.D. Student's $t$-tests were performed to calculate $p$ values
FMDV compared with cells derived from animals that are not natural hosts of FMDV. Previous studies have shown that IRES-mediated translational activity in CPK cells was higher than in MDBK cells, which may be due to efficient FMDV replication in swine cells [33]. In this study, although differences in IRES-mediated translational activity were observed among the cell lines, the translation activity of FMDV in FMDV-susceptible-host-derived cells was comparable to that of FMDV-insusceptible-host-derived cells. Furthermore, IRES-mediated translational activity in CPK cells was lower than that in MDCK cells, which were derived from canines (non-host animal of FMDV). Therefore, IRES-mediated translation activity cannot be used to accurately determine the host range of FMDV.

\section{The effects of cellular factors on IRES-mediated translation of FMDV}

The cellular factors ITAF and eIF play important roles in facilitating IRES-mediated translation [20-22]. However, these findings were obtained by using cell lines derived from FMDV-insusceptible animals.

Therefore, to analyze the effect of ITAFs and 4E-BP1, the expression of $\mathrm{ITAF}_{45}, \mathrm{PTB}$, and 4E-BP1 was inhibited using siRNAs. The effect of siRNA was assessed by western blot analysis (Fig. 3). Following siRNA treatment, cells were further transfected with the reporter plasmid and evaluated for IRES-mediated translational activity (Figs. 4, 5 and 6). We found that inhibition of ITAF $_{45}$ expression suppressed IRES-mediated translational activity in cell lines derived from both FMDV-susceptible and FMDV-insusceptible animals. Inhibition of PTB and 4E-BP1 reduced IRES-mediated translational activity only in the FMDV-susceptible host cell lines (MDBK $p<0.05$, and CPK $p<0.01$ ). Our results show silencing of $\mathrm{ITAF}_{45}$, PTB and 4E-BP1 in CPK cells can significantly suppress IRES-mediated translational activity.

\section{Discussion}

In this study, we evaluated IRES-mediated translational activity in HEK293, MDCK, MDBK, and CPK cells to determine whether this process differs between cells derived from FMDV-susceptible and FMDV-insusceptible animals. Although difference in IRES-mediated translational activity was observed among these cell lines, it was not predictive of FMDV host range. Thus, other cellular processes/interactions that are distinct from IRES-mediated translation are needed when determining the host range of FMDV. For example, it was recently reported that the amino acid sequence of integrin protein, which is a candidate FMDV receptor, is different between host and non-host animals [34]. In the host animals, there is also a difference in the expression of integrin proteins between FMDV-susceptible organs and FMDVinsusceptible organs [35]. Furthermore, diverse innate 


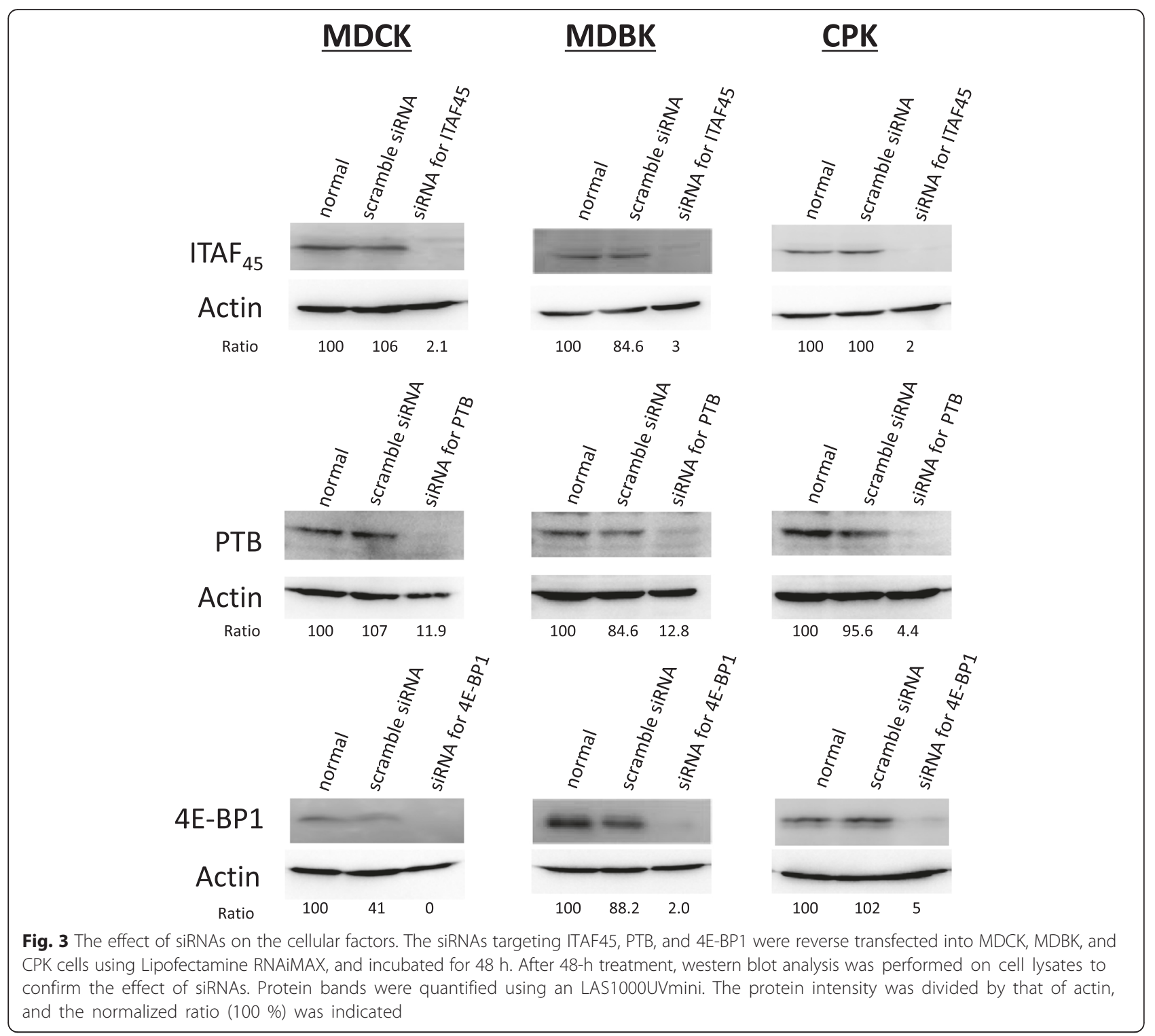

immune reactions have been shown to be initiated against FMDV infection in different animal species, including the host animals of FMDV [33]. The data obtained in this study indicate that IRES-mediated translation cannot be used to accurately define FMDV host range.

Next, we analyzed the effect of $\mathrm{ITAF}_{45}, \mathrm{PTB}$, and 4EBP1 on IRES-mediated translation of FMDV in cell lines derived from FMDV-susceptible and FMDV-insusceptible animals. Inhibition of ITAF $_{45}$ expression suppressed IRESmediated translation activity in all cell lines. However, silencing of PTB and 4E-BP1 suppressed IRES-mediated translation activity only in the cell lines derived from FMDV host animals. The active subunits of some cellular factors, including PTB, are generated by proteolysis, which has been correlated to FMDV-induced cytopathic effects [36]. Our findings from this study indicate that PTB, along with some other unidentified factors may be involved in facilitating IRES-mediated translation in FMDV-susceptible animals. The role of ITAFs in IRESmediated translation has not yet been thoroughly characterized. Additional studies are required to determine the role of ITAFs in regulating FMDV-susceptibility of cells through IRES-mediated translation.

The inhibition of 4E-BP1 expression suppressed IRESmediated translation activity in MDCK, MDBK, and CPK cells. These unexpected results suggest that IRESmediated translation is dependent on 4E-BP1 (indicated by decrease in firefly luciferase activity, data not shown). Overexpression of $4 \mathrm{E}-\mathrm{BP} 1$ has been previously shown to promote IRES-mediated translation of EMCV, and eIF4E availability has been shown to regulate IRES-mediated translation efficiency [37]. Although the translation of 


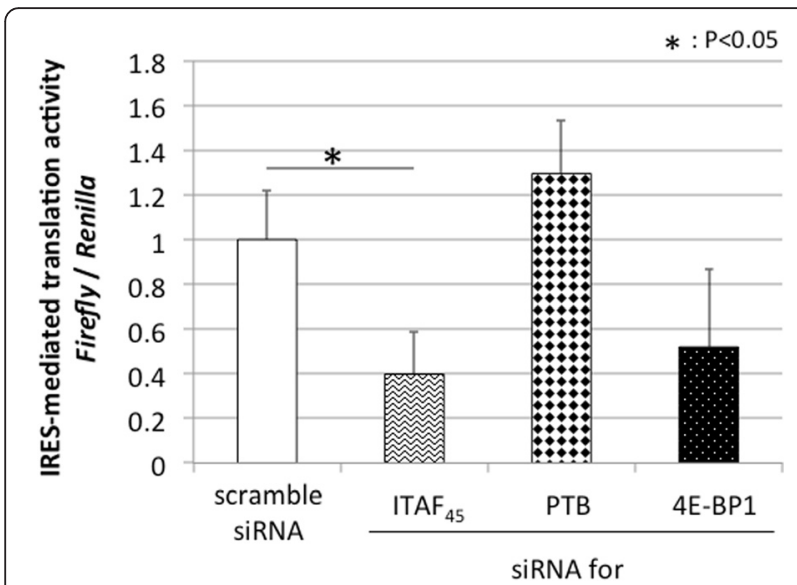

Fig. 4 The effect of siRNAs on IRES-mediated translation in MDCK cells. After $48 \mathrm{~h}$ of siRNA treatment, cells were further transfected with plasmid construct. $24 \mathrm{~h}$ following transfection, Renilla luciferase and firefly luciferase units were measured using the Dual-Luciferase Reporter Assay System and IRES-mediated translation activity in MDCK cells. Experiments were performed in triplicates and error bars indicate S.D

some viruses, such as poliovirus and vesicular stomatitis virus, has been shown to be promoted by phosphorylation of 4E-BP1, the translation of other viruses, such as adenovirus, has been shown to be promoted by dephosphorylation of 4E-BP1 [33, 38]. Furthermore, 4E-BP1 was previously shown to be involved in other cell activities such as regulation of cell growth and oncogenesis $[39,40]$. Together with

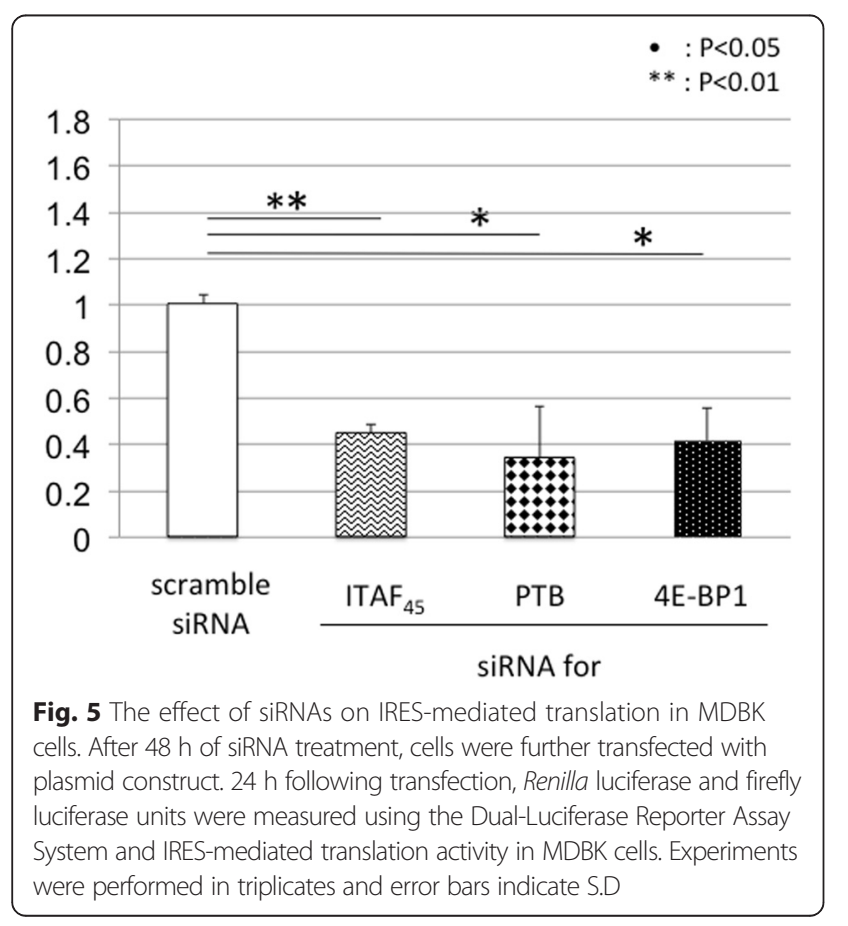

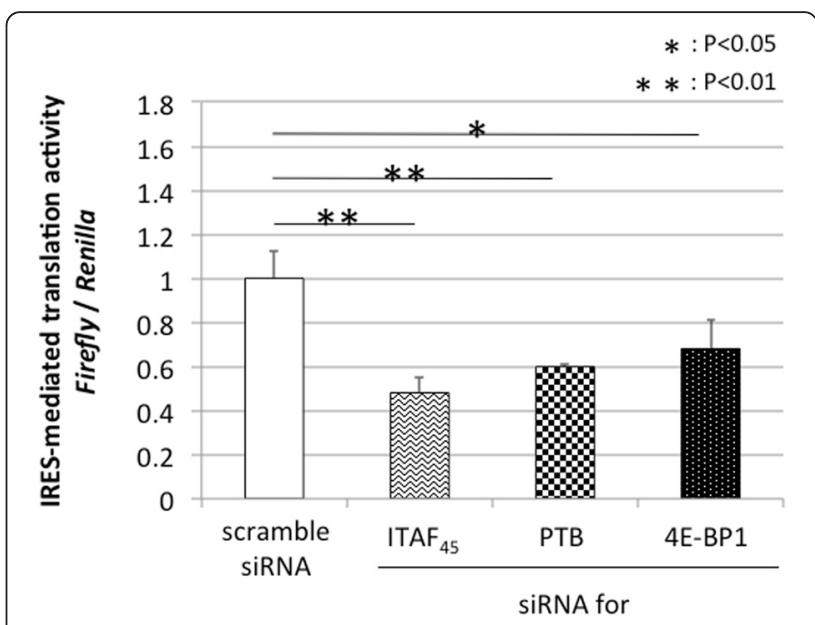

Fig. 6 The effect of siRNAs on IRES-mediated translation in CPK cells. After $48 \mathrm{~h}$ of siRNA treatment, cells were further transfected with plasmid construct. $24 \mathrm{~h}$ following transfection, Renilla luciferase and firefly luciferase units were measured using the Dual-Luciferase Reporter Assay System and IRES-mediated translation activity in CPK cells. Experiments were performed in triplicates and error bars indicate S.D

previous findings, our study indicates that 4E-BP1 regulates IRES-mediated translation of FMDV through complex mechanisms, and may play differential roles among various animal species. Further studies are required to characterize these potential novel functions of 4E-BP1.

\section{Conclusions}

IRES-mediated translation activity of FMDV was not predictive of its host range. ITAF $_{45}$ promoted IRESmediated translation in all cells, and the effects of PTB and 4E-BP1 were observed only in FMDVsusceptible cells. Eukaryotic initiation factor 4E-BP1 unexpectedly interacted with IRES-mediated translation in cells.

\section{Methods}

\section{Cell lines and culture}

The human kidney cell line (HEK293) and bovine kidney cell line (MDBK) used in this study were obtained from the American Type Culture Collection (ATCC), and were maintained in Dulbecco's modified Eagle's medium (DMEM; Nissui) supplemented with $10 \%$ fetal calf serum (FCS; Bovogen). The canine kidney cell line (MDCK) was originally from ATCC and was maintained in Eagle's minimum essential medium (MEM; Life Technologies) supplemented with $5 \%$ newborn calf serum (NCS; Hazleton). The porcine kidney cell line (CPK) [41] was maintained in MEM supplemented with $10 \%$ FCS. All cell lines were cultured at $37^{\circ} \mathrm{C}$ in $5 \% \mathrm{CO}_{2}$. 


\section{Plasmids}

The pRF/FMDV-IRES plasmids were kindly provided to us by Dr. Hirasawa (Memorial University of Newfoundland). Reporter genes were excised from pRF/FMDV-IRES using the restriction endonucleases EcoRV (Toyobo) and HpaI (NEB). pCAGGS/FMDV-IRES was generated by inserting a reporter gene into pCAGGS/ MSC(F), which was then treated with SmaI (Takara) and rAPid Alkaline Phosphatase (Roche) using Mighty Mix (Takara). DNA fragments were purified with the Big Dye XTerminator Purification kit, followed by sequencing via capillary electrophoresis on the $\mathrm{ABI}$ PRISM310 genetic analyzer.

\section{Short interfering RNA assay}

Short interfering RNAs (siRNAs) targeting human-ITAF 45 were used for MDCK, and MDBK cells. The siRNAs targeting mouse-ITAF ${ }_{45}$ were used for CPK cells. Both types of ITAF $_{45}$-targeting siRNAs were composed of a mixture containing 3 siRNAs with 19-25 nucleotides (Santa Cruz Biotechnology). The siRNAs targeting human-PTB and human-4E-BP1 were as follows: 5'-GGCAGGAAATTC TGTATTG-3', and 5'-GAGTCACAGTTTGAGATGGA CATTTAA-3', respectively (Life Technologies).

\section{Transfection}

Cells $\left(10^{5} /\right.$ well) were grown in 24 -well plates with culture medium for $24 \mathrm{~h}$ to achieve $50-70 \%$ confluency for transfection. Plasmid transfection was performed using Lipofectamine 2000 reagent (Invitrogen) according to manufacturer's specification. The siRNA reverse transfection was performed using Lipofectamine RNAiMIX reagent (Invitrogen) according to manufacturer's specification.

\section{Luciferase assay}

Cells were washed once with PBS (-), and lysed with passive lysis buffer (Promega). Renilla luciferase and firefly luciferase activities were measured using the DualLuciferase Reporter Assay System (Promega). Cell lysates $(10 \mu \mathrm{L})$ were mixed with a 10-fold diluted reagent $(100 \mu \mathrm{L})$, and luminescence was measured with the GloMax 96 Microplate for $10 \mathrm{~s}$. Luciferase activity was quantified as the relative fluorescent intensity in the 10-s interval.

\section{Western blot analysis}

Cells were washed twice with PBS, and lysed with RIPA buffer containing $0.1 \%$ SDS, $10 \mu \mathrm{g}$ aprotinin/mL, $100 \mu \mathrm{g}$ $\mathrm{PMSF} / \mathrm{mL}$ and $1 \%$ phosphatase inhibitor cocktail (Sigma). Cell lysates were subjected to SDS-PAGE, and the resolved proteins were transferred to a PVDF membrane (Millipore). The membrane was blocked with $5 \%$ Block Ace (Yukijirushi) in Tris buffered saline (TBS) containing $0.1 \%$ Tween-20, and was probed with the following primary antibodies: anti-ITAF45 (Santa Cruz Biotechnology),
anti-PTB (Cell Signaling), anti-4E-BP1 (Cell Signaling), and anti-ßactin (SIGMA)]. The membranes were then washed 3 times with $0.05 \%$ Tween- 20-TBS for $10 \mathrm{~min}$. Secondary antibodies (peroxidase-conjugated anti-rabbit or anti-mouse IgG; DAKO) were subsequently added, and specific protein bands were visualized with enhanced chemical luminescence (GE Healthcare).

\section{Statistical analysis}

All data are presented as means \pm SEM from three independent experiments. Statistical analysis was performed using Student's $t$-test to evaluate significant differences $\left({ }^{*} P<0.05,{ }^{* * *} P<0.01\right)$.

\section{Ethical approval and consent to participate}

All experiments were approved by the ethics committee of Kagoshima University. This study did not include animal experiments.

\section{Consent for publication \\ Not applicable.}

\section{Availability of data and materials \\ Data and materials are available upon request.}

Abbreviations

FMDV: Foot-and-mouth disease virus; IRES: Internal ribosomal entry site; 5' UTR: 5' untranslated region; ITAFs: IRES trans-acting factors; PTB: Poly-pyrimidine tract binding protein; 4E-BP1: 4E-binding protein1.

\section{Competing interests}

The authors do not have any financial or personal relationship with organizations or people that could influence the content or conclusions of the study.

\section{Authors' contributions}

TK performed experiment, KTK made experimental design, and MO and KTK wrote manuscript. All authors read and approved the final manuscript.

\section{Acknowledgement}

We would like to thank Dr. Hirasawa for providing the pRF/FMDV-IRES plasmid.

\section{Funding}

This study was supported by the grant from the ministry of education, science and culture, Japan (15 K14781).

Received: 29 September 2015 Accepted: 23 March 2016

Published online: 31 March 2016

\section{References}

1. Grubman MJ, Baxt B. Foot-and-mouth disease. Clin Microbiol Rev. 2004;17: 465-93.

2. Ryan E, Horsington J, Durand S, Brooks H, Alexandersen S, Brownlie J, Zhang Z. Foot-and-mouth disease virus infection in young lambs: pathogenesis and tissue tropism. Vet Microbiol. 2008;127:258-74.

3. Jamal SM, Belsham GJ. Foot-and-mouth disease: past, present and future. Vet Res. 2013:44:116

4. Belsham GJ, Brangwyn JK. A region of the $5^{\prime}$ noncoding region of foot-andmouth disease virus RNA directs efficient internal initiation of protein synthesis within cells: involvement with the role of $L$ protease in translational control. J Virol. 1990;64:5389-95.

5. Jackson RJ, Kaminski A. Internal initiation of translation in eukaryotes: the picornavirus paradigm and beyond. RNA. 1995;1:985-1000.

6. Tsukiyama-Kohara K, lizuka N, Kohara M, Nomoto A. Internal ribosome entry site within hepatitis C virus RNA. J Virol. 1992;66:1476-83. 
7. Lozano G, Martinez-Salas E. Structural insights into viral IRES-dependent translation mechanisms. Curr Opin Virol. 2015;12:113-20.

8. Shatkin AJ. mRNA cap binding proteins: essential factors for initiating translation. Cell. 1985:40:223-4.

9. Truniger V, Nieto C, Gonzalez-Ibeas D, Aranda M. Mechanism of plant elF4Emediated resistance against a Carmovirus (Tombusviridae): cap-independent translation of a viral RNA controlled in cis by an (a)virulence determinant. Plant J. 2008;56:716-27.

10. Miras M, Sempere RN, Kraft JJ, Miller WA, Aranda MA, Truniger V. Interfamilial recombination between viruses led to acquisition of a novel translationenhancing RNA element that allows resistance breaking. New Phytol. 2014;202:233-46.

11. Michon T, Estevez Y, Walter J, German-Retana S, Le Gall O. The potyviral virus genome-linked protein VPg forms a ternary complex with the eukaryotic initiation factors elF4E and elF4G and reduces elF4E affinity for a mRNA cap analogue. FEBS J. 2006;273:1312-22.

12. Eskelin K, Hafren A, Rantalainen Kl, Makinen K. Potyviral VPg enhances viral RNA Translation and inhibits reporter mRNA translation in planta. J Virol. 2011;85:9210-21.

13. Ziegler E, Borman AM, Deliat FG, Liebig HD, Jugovic D, Kean KM, Skern T, Kuechler E. Picornavirus 2A proteinase-mediated stimulation of internal initiation of translation is dependent on enzymatic activity and the cleavage products

of cellular proteins. Virology. 1995;213:549-57.

14. Borman AM, Kirchweger R, Ziegler E, Rhoads RE, Skern T, Kean KM. elF4G and its proteolytic cleavage products: effect on initiation of protein synthesis from capped, uncapped, and IRES-containing mRNAs. RNA. 1997;3:186-96.

15. Moral-Lopez P, Alvarez E, Redondo N, Skern T, Carrasco L. L protease from foot and mouth disease virus confers elF2-independent translation for mRNAs bearing picornavirus IRES. FEBS Lett. 2014;588:4053-9.

16. Kieft JS. Viral IRES RNA structures and ribosome interactions. Trends Biochem Sci. 2008:33:274-83.

17. Filbin ME, Kieft JS. Toward a structural understanding of IRES RNA function Curr Opin Struct Biol. 2009:19:267-76.

18. Martinez-Salas E. The impact of RNA structure on picornavirus IRES activity. Trends Microbiol. 2008;16:230-7.

19. Yu Y, Abaeva IS, Marintchev A, Pestova TV, Hellen CU. Common conformational changes induced in type 2 picornavirus IRESs by cognate trans-acting factors. Nucleic Acids Res. 2011;39:4851-65.

20. Pilipenko EV, Pestova TV, Kolupaeva VG, Khitrina EV, Poperechnaya AN, Agol VI, Hellen CU. A cell cycle-dependent protein serves as a templatespecific translation initiation factor. Genes Dev. 2000;14:2028-45.

21. Andreev DE, Fernandez-Miragall O, Ramajo J, Dmitriev SE, Terenin IM, Martinez-Salas E, Shatsky IN. Differential factor requirement to assemble translation initiation complexes at the alternative start codons of foot-and-mouth disease virus RNA. RNA. 2007;13:1366-74.

22. Monie TP, Perrin AJ, Birtley JR, Sweeney TR, Karakasiliotis I, Chaudhry Y Roberts LO, Matthews S, Goodfellow IG, Curry S. Structural insights into the transcriptional and translational roles of Ebp1. EMBO J. 2007;26:3936-44.

23. Deforges J, Locker N, Sargueil B. mRNAs that specifically interact with eukaryotic ribosomal subunits. Biochimie. 2015;114:48-57.

24. Pause A, Belsham GJ, Gingras AC, Donze O, Lin TA, Lawrence Jr JC, Jr., Sonenberg N. Insulin-dependent stimulation of protein synthesis by phosphorylation of a regulator of 5'-cap function. Nature. 1994:371:762-7.

25. Tsukiyama-Kohara K, Poulin F, Kohara M, DeMaria CT, Cheng A, Wu Z, Gingras AC, Katsume A, Elchebly M, Spiegelman BM, et al. Adipose tissue reduction in mice lacking the translational inhibitor 4E-BP1. Nat Med. 2001; 7:1128-32.

26. Sekiyama N, Arthanari H, Papadopoulos E, Rodriguez-Mias RA, Wagner G, Leger-Abraham M. Molecular mechanism of the dual activity of $4 \mathrm{EGI}-1$ : Dissociating elF4G from elF4E but stabilizing the binding of unphosphorylated 4E-BP1. Proc Natl Acad Sci U S A. 2015;112:E4036-45.

27. Pyronnet S, Imataka H, Gingras AC, Fukunaga R, Hunter T, Sonenberg N. Human eukaryotic translation initiation factor $4 \mathrm{G}$ (elF4G) recruits mnk1 to phosphorylate elF4E. EMBO J. 1999;18:270-9.

28. Fernandez J, Yaman I, Mishra R, Merrick WC, Snider MD, Lamers WH, Hatzoglou M. Internal ribosome entry site-mediated translation of a mammalian mRNA is regulated by amino acid availability. J Biol Chem. 2001;276:12285-91.
29. Gingras AC, Svitkin Y, Belsham GJ, Pause A, Sonenberg N. Activation of the translational suppressor 4E-BP1 following infection with encephalomyocarditis virus and poliovirus. Proc Natl Acad Sci U S A. 1996;93:5578-83.

30. Licursi M, Komatsu Y, Pongnopparat T, Hirasawa K. Promotion of viral internal ribosomal entry site-mediated translation under amino acid starvation. J Gen Virol. 2012;93:951-62.

31. Connor JH, Lyles DS. Vesicular stomatitis virus infection alters the elF4F translation initiation complex and causes dephosphorylation of the elF4E binding protein 4E-BP1. J Virol. 2002;76:10177-87.

32. Czudai-Matwich V, Schnare M, Pinkenburg O. A simple and fast system for cloning influenza A virus gene segments into pHW2000- and pCAGGSbased vectors. Arch Virol. 2013;158:2049-58.

33. Toka FN, Golde WT. Cell mediated innate responses of cattle and swine are diverse during foot-and-mouth disease virus (FMDV) infection: a unique landscape of innate immunity. Immunol Lett. 2013:152:135-43.

34. Du J, Gao S, Chang H, Cong G, Lin T, Shao J, Liu Z, Liu X, Cai X. Bactrian camel (Camelus bactrianus) integrins alphavbeta3 and alphavbeta6 as FMDV receptors: molecular cloning, sequence analysis and comparison with other species. Vet Immunol Immunopathol. 2009;131:190-9.

35. Zhu JJ, Arzt J, Puckette MC, Smoliga GR, Pacheco JM, Rodriguez LL. Mechanisms of foot-and-mouth disease virus tropism inferred from differential tissue gene expression. PLoS One. 2013:8:e64119.

36. Rodriguez Pulido M, Serrano P, Saiz M, Martinez-Salas E. Foot-and-mouth disease virus infection induces proteolytic cleavage of PTB, elF3a, b, and PABP RNA-binding proteins. Virology. 2007;364:466-74.

37. Svitkin YV, Herdy B, Costa-Mattioli M, Gingras AC, Raught B, Sonenberg N. Eukaryotic translation initiation factor $4 \mathrm{E}$ availability controls the switch between cap-dependent and internal ribosomal entry site-mediated translation. Mol Cell Biol. 2005;25:10556-65.

38. Gingras AC, Sonenberg N. Adenovirus infection inactivates the translational inhibitors 4E-BP1 and 4E-BP2. Virology. 1997;237:182-6.

39. Petroulakis E, Parsyan A, Dowling RJ, LeBacquer O, Martineau Y, Bidinosti M, Larsson O, Alain T, Rong L, Mamane Y, et al. p53-dependent translational control of senescence and transformation via 4E-BPs. Cancer Cell. 2009;16: $439-46$.

40. She QB, Halilovic E, Ye Q, Zhen W, Shirasawa S, Sasazuki T, Solit DB, Rosen N. 4E-BP1 is a key effector of the oncogenic activation of the AKT and ERK signaling pathways that integrates their function in tumors. Cancer Cell. 2010; 18:39-51.

41. Komaniwa H, Fukusho A, Shimizu Y. Micro method for performing titration and neutralization test of hog cholera virus using established porcine kidney cell strain. Natl Inst Anim Health Q (Tokyo). 1981;21:153-8.

\section{Submit your next manuscript to BioMed Central and we will help you at every step:}

- We accept pre-submission inquiries

- Our selector tool helps you to find the most relevant journal

- We provide round the clock customer support

- Convenient online submission

- Thorough peer review

- Inclusion in PubMed and all major indexing services

- Maximum visibility for your research

Submit your manuscript at www.biomedcentral.com/submit 